\title{
Transnational comparability of advanced pharmacy practice developmental frameworks: A country-level crossover mapping study.
}

Udoh, A.; Bruno, A.; Bates, I.; Galbraith, K.

FIP Collaborating Centre, UCL School of Pharmacy, London, UK and Faculty of Pharmacy and Pharmaceutical Sciences, Monash University, Melbourne, Australia.

First published: 4 January 2018

DOI: $10.1111 /$ ijpp. 12427

\begin{abstract}
Background: Previous work by the International Pharmaceutical Federation Education Initiative (FIPEd) demonstrates that even though some country-specific variations occur in pharmacy practice, there exists a set of practice-related competencies that are globally applicable. This study aimed to evaluate the transnational comparability of the Royal Pharmaceutical Society Advanced Pharmacy Framework (RPS-APF, Great Britain), and the Advanced Pharmacy Practice Framework for Australia (APPF). The objective was to obtain preliminary data on the transnational applicability of the developmental competencies contained in the two frameworks.
\end{abstract}

Method: A crossover mapping study involving 42 advanced level pharmacists from four countries was conducted. Qualitative interview $(n=17)$ was also carried out to explore practitioners' perception of the frameworks.

Result: The average post-registration experience of the practitioners in the crossover study was 19 years. Directly observed within-subject agreement per advanced practice competency ranged from $45 \%$ to $86 \%$. This agreement was significant for $87 \%$ of the competencies evaluated $(k \geq 0.21 ; \mathrm{p} \leq 0.05)$. The lowest agreement was in the "governance" competency $(k=0.13 ; \mathrm{p}=0.21)$. Wilcoxon sum rank test showed a statistically significant within-subject difference in the "collaborative practice" cluster $(\mathrm{p}=0.043)$. This was not observed in the other five advanced practice clusters. From the qualitative interviews, practitioners generally perceived the two compared advanced level frameworks as similar in content and indicated they found the described competencies to be useful for clarifying expectations of practice and identifying skills development needs.

Conclusion: These findings provide preliminary evidence of the comparability and 
transnational applicability of the advanced pharmacy practice competencies contained in the two national competency development frameworks evaluated. 
2 The International Pharmaceutical Federation Education Initiative (FIPEd) developed the FIP

3 Global Competency Framework (GbCF v1) in $2012^{1}$. This framework was specifically 4 designed to provide global guidance on the practice-based expectations of foundation level 5 pharmacy practice. In this context, foundation level practice refers to pharmacists with 6 generally less than three years post-registration experience, or those returning to practice. 7 Ongoing validation of this developmental framework has demonstrated the relevance and 8 validity of the GbCF v1 competencies in 64 countries around the world ${ }^{2}$. This suggests that even though some country-specific variations occur in pharmacy practice, there exists a set of practice-related competencies that are globally applicable for foundation practice development.

The finding is in line with existing evidence from the field of medicine that has shown transnational applicability of the Canadian CanMEDS Physician Competency Framework to medical practice in Netherlands ${ }^{3}$, Denmark ${ }^{4,5}$ and Australia ${ }^{6}$. It also corroborates evidence from previous research that demonstrate the applicability of the General Level Framework (developed in the United Kingdom, a precursor to the Foundation Pharmacy Framework ${ }^{7}$ ) to pharmacy practice in Croatia ${ }^{8}$, Serbia ${ }^{9}$, Australia ${ }^{10}$ and Singapore ${ }^{11}$.

Since its development, the GbCF v1 has been successfully used to design pre-service education and training curriculum for undergraduate pharmacy students ${ }^{12}$. Also, Ireland ${ }^{13}$, the Pacific Island Countries ${ }^{14}$, Serbia and Singapore have developed national frameworks for foundation pharmacy level that are linked to the GbCF v1 ${ }^{12}$. The transnational validation of the GbCF v1 alongside similar evidence from the field of medicine underscores the feasibility and relevance of a developmental framework that maps the expectations of professional practice for a global pharmacy workforce. Further work is necessary to identify the transnational validity of the core competencies required of an advanced (post foundation) pharmacy workforce.

Advanced pharmacy practice is generally held as that relating to practice that is implicitly different from that achieved at initial registration ${ }^{15}$. Advanced practice can be, or should be, demonstrably more complex with higher associated capabilities which can be professionally recognised. This is particularly important in view of the global changing healthcare environments where aging populations have resulted in increased prevalence of chronic and co-morbid diseases that demand complex care services. Therefore, the availability of a 
pharmacy workforce that is capable of providing complex evidenced-based medicines expertise and pharmaceutical care services is essential.

A global survey of pharmacy organisations and professional bodies conducted by FIPEd identified the existence of practitioner development frameworks for pharmacy practice in twenty-seven countries ${ }^{16}$. United Kingdom and Australia were the two countries with published national developmental frameworks for advanced pharmacy practice ${ }^{15}$. The frameworks: the Royal Pharmaceutical Society Advanced Pharmacy Framework (RPS-APF) and the Advanced Pharmacy Practice Framework for Australia (APPF), were developed and mapped to population needs in United Kingdom and Australia respectively ${ }^{17,18}$. Further systematic literature searching, and a survey conducted in 2015 (updated in 2016), did not yield additional published national frameworks for advanced pharmacy practice, even though some countries indicated the existence and national recognition of pharmacy specialties ${ }^{15}$.

Content mapping, via a thematic analysis technique identified six competency themes (these were the competency "clusters") and 30 sub-themes (these were the developmental - or behavioural competencies) common to the RPS-APF and APPF frameworks ${ }^{19}$. In total, 64 advanced pharmacy practice competencies were identified in the two frameworks with 34 contained in the RPS-APF and 30 in the $\mathrm{APPF}^{19}$. These competencies were commonly described across three "levels" or "stages" of advanced pharmacy practice in both frameworks: 'advanced stage 1', 'advanced stage II', and 'mastery' in the RPS-APF; and 'transition', 'consolidation', and 'advanced level' in the APPF (Appendix 1).

A matrix of the competencies and descriptors in the RPS-APF cross-matched semantically with corresponding competencies and descriptors in the APPF was created from the mapping process $^{19}$ (Appendix 2). The output of the framework mapping was presented to a panel of international pharmacy experts $(n=14)$ from nine countries for a review ${ }^{19}$. Consensus from the expert group developed via a modified Delphi technique indicated broad similarity in advanced practice competencies and descriptors between the two frameworks ${ }^{19}$, further corroborating existing evidence ${ }^{20}$.

The goal of this study was to evaluate the transnational comparability of the two frameworks. The objective was to obtain preliminary data on transnational applicability of the developmental competencies contained in these advanced level frameworks. 


\section{Method}

This study was conducted in two phases. Phase 1 was a crossover study while qualitative interviews were conducted in phase 2 .

\section{Sampling and data collection}

A convenience sample of practitioners from New Zealand, United Kingdom, Australia and Ireland was used for this study. These were the countries identified to be actively involved in formal articulation of advanced level pharmacy practice ${ }^{16}$. The pharmacy professional bodies in these countries assisted with the project by disseminating study invitations to their respective members via email. Participating organisations were the Pharmaceutical Society of Australia (PSA), Society of Hospital Pharmacists of Australia (SHPA), Royal Pharmaceutical Society of Great Britain, United Kingdom Clinical Pharmacy Association (UKCPA) and Pharmaceutical Society of New Zealand (PSNZ). A minimum practice experience threshold of 5 years was chosen for this study based on the consensus definition of advanced pharmacy practice ${ }^{18(\mathrm{p} 11)}$. Interested practitioners were requested to contact the study authors $\mathrm{AU}$ or $\mathrm{AB}$ using the details included in the invitation. Practitioners who expressed interest to participate were assessed for eligibility. Consent and enrollment forms were then forwarded by $\mathrm{AU}$ to the eligible practitioners with enrollment completed on receipt of the signed forms. This study was conducted between February and August 2014 with none of the participants indicating they had undergone prior advanced practice credentialing in Australia or Great Britain. Figure 1 shows flow chart of the participant recruitment process.

\section{Crossover study design}

A simple random allocation software was used to randomise study participants to either of two groups: A or B. Participants self-assessed and mapped their practice on to one of the identified frameworks at a specified time $\left(\mathrm{T}_{1}\right)$. After a three-month 'wash out' period, the same group of practitioners then carried out a second self-assessment using the alternative framework $\left(T_{2}\right)$. The three-month washout period between the first and second assessment was calculated respectively for each participant.

Each framework was fully reproduced and distributed via email as a questionnaire with the inclusion of checkboxes for use by participants to self-assess their level of practice for each competency (please see supplementary material Appendix 3 and 4). Participants used the checkboxes provided to indicate their self-assessed level of practice per competency including 
the type of 'portfolio' evidence they had available to support their assessment. A checklist of 12 sample portfolio evidences was provided for each of the competencies with participants required to check as many evidence categories as available to support their individual assessment. Completed documents were returned electronically.

\section{Interviews}

The participants who completed the two self-assessments required for the study were invited via email to participate in a semi-structured telephone interview. Interview time was agreed between $\mathrm{AU}$ and each participant who indicated willingness to be interviewed. An email reminder was forwarded to each participant prior to the interview date. The aim of the interview was to explore participant perception of the two frameworks used with respect to content and layout. It also aimed to obtain input on the self-assessment process (please see interview schedule in appendix 5). Participants were interviewed until redundancy. Verbal consent for audio recording was obtained from the participants at the start of the conversation. The telephone interviews each lasted for 15-20 minutes and the recordings were transcribed verbatim. A copy of the interview transcript was forwarded to the respective participants to confirm validity.

\section{Data analysis}

The matrix of competencies created from the initial semantic framework mapping ${ }^{19}$ (Appendix 2) was used for the analysis. The objective of the analysis was to assess individual ranking of matching competencies in the two frameworks. Within-subject agreement in ranking between matching competencies in the frameworks was assumed to be indicative of parity for that competency. Observed agreement was expressed using percentages. Kappa statistic (k) was used to evaluate chance-corrected within-subject agreement (statistical significance was set at $P \leq 0.05)$. Values of $0<k<0.20$ indicated slight or poor agreement; $0.21<k<0.40$ fair agreement; $0.41<k<0.60$ moderate agreement; $0.61<k<0.80$ substantial or good agreement; $k \geq 0.81$ excellent agreement; and $k=1$ indicated perfect statistical agreement ${ }^{21-23}$. Exploratory analysis using the Wilcoxon sum-ranked test was also conducted to evaluate difference in withinsubject ranking of competencies. 
133 The interview transcripts obtained in the second part of this study were coded and analysed 134 using a thematic analysis technique as previously described by Braun and Clarke ${ }^{24}$. The 135 thematic coding was conducted independently by $\mathrm{AU}$ and $\mathrm{AB}$ with the results compared to 136 ensure credibility and reliability. 


\section{Crossover mapping study}

140

141

142

\section{Demography}

After randomisation, twelve participants indicated they were unable to complete the first assessment within the time required and dropped out. Also, two other participants were unable to complete the second assessment due to role changes and these also dropped out of the study. In total, 42 pharmacists from four countries completed the two self-assessments required for the crossover study (Table 1). This included 15 participants each from Australia and New Zealand, 11 from United Kingdom and one participant from Ireland. Majority (93\%) of the study participants were in hospital practice. Community, academic and primary care pharmacy practice each had one participant represented. Mean length of practice was 19 years [SD: 11; Min-Max: 5-52years]. More than half (57\%) of the study participants indicated they were leading-edge practitioners (please see Appendix 1 for definition of level of practice).

Observed agreement ranged from $45 \%(\mathrm{~N}=19)$ in the 'national priorities' competency to $86 \%$ $(\mathrm{N}=36)$ in the 'reasoning \& judgement' competency (Table 2). The $k$-values indicated fair $(0.21<k<0.40)$ to moderate $(0.41<k<0.60)$ agreement for a majority ( $\mathrm{n}=26(87 \%))$ of the matching competencies evaluated. The $k$-values were also significant $(\mathrm{p}<0.05)$ for all of the competencies, except the 'governance' and 'national priorities' competencies (Table 2). Wilcoxon sum-rank test showed a statistically significant within-subject difference in the collaborative practice cluster $(\mathrm{p}=0.043)$. This was not observed in the other five clusters, although the median ranks were lower in the first assessment for the 'leadership', 'management' and 'evaluation and research' clusters (Table 3).

Disparity in the evidence used to support self-assessment was observed between the three cadres of advanced practice described in the two frameworks and across the identified clusters. Although the $95 \% \mathrm{CI}$ overlapped, the trend did indicate that "leading edge" practitioners are more likely to be members of international, or regional committees, and are more likely to be involved in research. This is in contrast to the "experienced" practitioners who were mostly involved in staff management and in education and teaching roles. "Specialist-in-training" practitioners were generally least able to support their self-assessments (Figure 2 and 3).

\section{(1)}


This included seventeen participants in total with participants from the four countries in the study represented (7 from Australia, 4 from New Zealand, 5 from United Kingdom and 1 from Ireland).

\section{Prior self-assessment experience}

Most of the interviewees (53\%) did not have formal self-assessment experience prior to the study.

No, this was the first time I have done a self-assessment. Ever since I completed my post-graduate diploma, which was basically mapped against the General Level Framework of the United Kingdom, I haven't used anything else to sort of guide my development or see where I am. So this was the very first time that I had to use slightly different tools to look at my practice.

A48, experienced practitioner, $U K$

Some of those with no prior self-assessment experience were interested and motivated to do so in this study because they thought it would be a useful process.

'No, I have never done something (self-assessment) like this before. Though I have been in a management position for just over two years; I never thought of doing something like this ... when I saw the advertisement by our hospital pharmacy society, I thought it would be useful to give it a go, just to see where my practice was'.

\section{A55, leading edge practitioner, Australia}

\section{Perceptions about the frameworks}

The interviewees indicated they thought the two frameworks were similar in description of competencies.

'... Without being too detailed, I think they were both quite similar in a lot of ways. There was a lot of duplication between them ... generally I would say that the wordings of the framework were quite similar'. 
'I found the frameworks to be very similar and didn't really see much difference. I know there was some gaps between doing the two assessments, but I do recall finding them to be similar in terms of wordings and description'.

B50, leading edge practitioner, New Zealand

They however reported some difficulties completing the framework in the first round but were more comfortable with the self-assessment process in the second round.

'I felt a bit lost the first time; I thought it was a bit difficult to comprehend. But by the second time I was quite familiar with the logic of the framework and knew what to do'.

A55, leading edge practitioner, Australia

'Even though I was quite familiar with the frameworks and evidence, I found it time consuming and difficult to do. I would say it was difficult to really get an accurate picture of it without spending a lot of time putting some sort of reflection into it, which is what I did in the first round. But by the second time I didn't have to reflect so much on what the statements meant and what evidence to include since I had already gone through the process.'

B5, leading edge practitioner, UK

Some thought reflection and exposure to the framework in the first round might have made completing the second assessment easier

'When I first saw the framework, I thought wow ... it felt a little bit overwhelming but when I read through the instructions and gave myself time to reflect, I felt more comfortable. The second round was a lot easier maybe because I sort of knew what the format was'.

B11, leading edge practitioner, New Zealand 
Others specifically expressed difficulty with identifying appropriate evidence for use in supporting self-assessment.

'What I did find slightly difficult was selecting the right categories that my evidence goes into. I had to refer back to information you sent about all the different meanings and I don't think all my evidence kind of neatly fitted into all the categories that were given. So, that probably was more difficult'.

\section{A35, experienced practitioner, Australia,}

They also indicated that this initial difficulty might have resulted in them underestimating their perceived level of competence on some competencies.

'I had an incidence the other day involving a work colleague ... in the end I found myself thinking that maybe I had underestimated my competence. I found myself thinking that may be if I actually searched through my hard drive and found everything I have done, maybe I would have more evidence than I gave myself credit for'.

A35, experienced practitioner, Australia

\section{Impact and relevance of the framework and self-assessment process}

The interviewees generally had positive opinions about the self-assessment process. They found the assessments to be useful in identifying practice gaps while also providing a road map for practice development.

'I found the two self-assessments useful in identifying gaps in my practice that may limit my ability to become an advance practitioner. They also pointed out for me areas of advance practice that my current position does not offer, example master level competencies and making an impact at a national level'. 
'It was a useful process because it helped me identify some areas where I haven't done any particular work for one reason or the other; it gave me ideas about developing my practice in those areas'.

A48, experienced practitioner, UK

275

'I found the framework to be a methodical way to look at a portfolio of professional activity. I don't think I would intuitively look at all the different dimensions and areas that the framework prompted me to do. So I actually found that very constructive and really useful and made me realise the breath of activity and how they could contribute 
The results of the crossover study showed observed and chance corrected agreement for the majority $(87 \%)$ of the developmental competencies in the national frameworks. Although the chance corrected agreement was relatively lower than the observed agreement (Table 2), this may be due to the known k-statistic property of generally underestimating observed agreement ${ }^{25,26}$. While there were inconsistencies in the ranking of competencies in three of the clusters evaluated (Table 3), the results of the Wilcoxon signed-ranked test showed these were not statistically significant in all but one competency in the frameworks.

The convenience sampling technique and the use of self-selected participants in this study limits the generalisability of the findings, especially because studies show that self-selected participants are likely to be more intrinsically motivated than the general population ${ }^{34}$. Given that majority (93\%) of the study participants were in hospital practice, future research involving advanced pharmacy practitioners from practice areas like community, academic and industrial pharmacy, and from other countries not represented is needed to add to the evidence base. Similarities between the pharmacy practice model in United Kingdom, Australia and New Zealand may be another source of bias in this study. However, with emerging evidence showing broad similarities in pharmacy practice-related competencies globally ${ }^{2}$, it can be argued that the results are likely to be applicable to practice in mid- and low income countries.

Even though the overall study results showed inconsistencies in ranking that were not statistically significant; the output in the analysis does indicate that the participants were likely to underestimate their 'level' competence in the first assessment. It suggests an initial lack of self-awareness of the breadth and depth of practice prior to exposure to the framework. This corroborates the results from the qualitative interviews which indicated that the opportunity for reflection and exposure to the competencies in the first 'exposed' framework likely aided accurate assessment of competence with the second exposure to a framework. Evidence from published literature ${ }^{27}$ suggest this may be due to task familiarity in the second assessment. This finding is in contrast to existing evidence ${ }^{28}$ indicating that "learners" tend to overestimate their abilities, although, the authors of the study also reported that overestimation was generally attenuated by further training and increased self-awareness of gaps in practice (which may be more particularly important with foundation - or less experienced - 'learners' and not generalizable to advanced, experienced practitioners). 
324 Furthermore, since the results in this study showed that some of the study participants ranked their practice higher in the second self-assessment (Table 3), it is possible that the opportunity for reflection provided by the first assessment may have heightened self-awareness of depth and limitation of practice. Evidence from the qualitative interviews corroborates this finding; further emphasising the need to promote reflective practice and routine self-assessment for continually developing pharmacy practitioners. Reflective practice can promote self-awareness of gaps in practice and facilitate self-directed learning for continuous professional development. Potentially, it could ensure that pharmacists are continuously self-aware of their capabilities and possibly provide the motivation and confidence needed to take on more responsibilities. Ultimately, this would aid the efficient use of available pharmaceutical skills and expertise, and is the prima facie reason for the use of developmental frameworks as a continuous career skill escalator tool.

On the other hand, the observed change in ranking may have been potentiated by the carryover effect inherent in crossover studies ${ }^{29,30}$. This is in line with evidence that demonstrate improvement in understanding and greater confidence in perceived level of competence after a four-day competency-based training workshop involving a group of health professionals ${ }^{31}$.

Evaluation of the evidence used to support self-assessment demonstrates the two frameworks are capable of differentiating between the three distinct cadres of advanced pharmacy practice identified in the two frameworks. This corroborates evidence from previous research ${ }^{32}$ and is in line with the practice profile expected of the different cadres of advanced practitioners ${ }^{18(\mathrm{p} 11)}$. Overall, the study results indicate a minimal disparity between the competencies in the two national frameworks and demonstrates a commonality of advanced developmental competencies that are applicable for advanced pharmacy practice in different countries as suggested by previous research ${ }^{2,8,9,10,32}$. From a policy perspective, the initial difficulties with using and understanding the terms in the frameworks suggests that training on the selfassessment process and the use of frameworks is essential and this will assist in ensuring that these tools are used effectively by practitioners.

\section{Conclusion}

This study provides preliminary evidence of transnational applicability of the competencies in two nationally developed advanced practice frameworks (the RPS-APF and the Australian 
358 APPF). In light of similar evidence from other studies looking at specific and specialized 359 competencies ${ }^{35,36}$, our results also suggest that the two advanced pharmacy frameworks 360 evaluated here can be used as core mapping tools for the development of other country-specific 361 frameworks. 


\section{REFERENCES}

1. FIP Education Initiatives. A Global Competency Framework for Services Provided by Pharmacy Workforce. International Pharmaceutical Federation; 2012.

2. Bruno AF. The feasibility, development and validation of a global competency framework for pharmacy education. PhD Thesis. School of Pharmacy, University of London. August 2011.

3. Scheele $\mathrm{F}$ et al. Introducing competency-based postgraduate medical education in the Netherlands. Med Teach. 2008;30(3):248-253. doi:10.1080/01421590801993022.

4. Danish Health and Medicines Authority. The seven roles of physicians. 2014. https://www.sst.dk/en/news/2013/ /media/39D3E216BCBF4A9096B286EE44F03691.a shx. Accessed January 13, 2017.

5. Ringsted $\mathrm{C}$ et al. Are some of the challenging aspects of the CanMEDS roles valid outside Canada? Med Educ. 2006;40(8):807-815. doi:10.1111/j.13652929.2006.02525.x.

6. The Royal Australian and New Zealand College of Psychiatrists. Fellowship Statements and Competencies. Melbourne, Australia: The Royal Australian and New Zealand College of Psychiatrists; 2012:3. https://www.ranzcp.org/Files/PreFellowship/2012Fellowship-Program/Fellowship-Competencies.aspx. Accessed January 13, 2017.

7. The Royal Pharmaceutical Society of Great Britain. The RPS Foundation Pharmacy Framework. The Royal Pharmaceutical Society of Great Britain; 2014. https://www.rpharms.com/Portals/0/RPS\%20document\%20library/Open\%20access/Fra meworks/RPS\%20Foundation\%20Pharmacy\%20Framework.pdf

8. Meštrović A et al. Individualized education and competency development of Croatian community pharmacists using the General Level Framework. Am J Pharm Educ. 2012;76(2):23. doi:10.5688/ajpe76223.

9. Svetlana $\mathrm{S}$ et al. Evaluation of competences at the community pharmacy settings. Indian J Pharm Educ Res. 2014;48(4):22-30. doi:10.5530/ijper.48.4.4.

10. Coombes I et al. Improvement in pharmacist's performance facilitated by an adapted competency-based general level framework. J Pharm Pract Res. 2010;40(2):111-118.

11. Rutter V et al. Use of a General Level Framework to facilitate performance improvement in hospital pharmacists in Singapore. Am J Pharm Educ. 2012;76(6):107. doi:10.5688/ajpe766107.

12. International Pharmaceutical Federation (FIP). 2013 FIPEd Global Education Report. The Hague, Netherlands: International Pharmaceutical Federation; 2013. 
13. The Pharmaceutical Society of Ireland. Core Competency Framework for Pharmacists. Dublin, Ireland: Pharmaceutical Society of Ireland; 2013. http://www.thepsi.ie/Libraries/Publications/PSI_Core_Competency_Framework_for_Ph armacists.sflb.ashx.

14. Brown AN, Gilbert BJ, Bruno AF, BPharm GMC. The Pharmacy Competency Framework for Pacific Island Countries. J Pharm Pract Res. 2012;42(4):268-272. doi:10.1002/j.2055-2335.2012.tb00186.x.

15. International Pharmaceutical Federation (FIP). Advanced Practice and Specialisation in Pharmacy: Global Report 2015. The Hague, Netherlands: International Pharmaceutical Federation; 2015.

http://www.fip.org/files/fip/PharmacyEducation/Adv_and_Spec_Survey/FIPEd_Advanc ed_2015_web_v2.pdf.

16. International Pharmaceutical Federation. The 2012 FIP Global Pharmacy Workforce Report. The Hague, Netherlands: International Pharmaceutical Federation; 2012.

17. Royal Pharmaceutical Society of Great Britain. The Development of the RPS Advanced Pharmacy Framework: A Report of the Processes, Methods and Findings with Plans for Future Work. London, UK: Royal Pharmaceutical Society of Great Britain; 2013. http://www.rpharms.com/faculty-documents/development-of-apf-report.pdf.

18. The Advanced Pharmacy Practice Framework Steering Committee (APPFSC). An Advanced Pharmacy Practice Framework for Australia. Canberra: Pharmaceutical Society of Australia; 2012:28. http://advancedpharmacypractice.com.au/download/framework/advanced-pharmacypractice-framework.pdf.

19. Udoh AE. Identifying and evaluating foundation and advanced pharmacy practice competencies in a global context. PhD Thesis. University College London School of Pharmacy. London. 2016.

20. Jackson S et al. An Advanced Pharmacy Practice Framework for Australia. Pharmacy. 2015;3:13-26.

21. Cohen J. A coefficient of agreement for nominal scales. Educ Psychol Meas. 1960;20:37-46.

22. Landis J, Koch G. The measurement of observer agreement for categorical data. Biometrics. 1977;33:159-174.

23. Viera AJ, Garrett JM. Understanding interobserver agreement: the Kappa statistic. Fam Med. 2005;37(5):360-363. 
24. Braun V, Clarke V. Using thematic analysis in psychology. Qual Res Psychol. 2006;3(2):77-101. doi:10.1191/1478088706qp063oa.

25. Cicchetti DV, Feinstein AR. High agreement but low kappa II: resolving the paradoxes. J Clin Epidemiol. 1990;43(6):551-558. doi:10.1016/0895-4356(90)90159-M.

26. Feinstein AR, Cicchetti DV. High agreement but low Kappa I: the problems of two paradoxes. J Clin Epidemiol. 1990;43(6):543-549. doi:10.1016/0895-4356(90)90158-L.

27. Fitzgerald J et al. A longitudinal study of self-assessment accuracy. Med Educ. 2003;37:645-649.

28. Kruger J, Dunning D. Unskilled and unaware of it: how difficulties in recognizing one's own incompetence lead to inflated self-assessments. J Pers Soc Psychol. 1999;77(6):1121-1134. doi:10.1037/0022-3514.77.6.1121.

29. Jones B, Kenward MG. Design and Analysis of Crossover Trials. 2nd ed. CRC Press; 2003.

30. Mills EJ et al.. Design, analysis and presentation of crossover trials. Trials $J$. 2009;10(1):27. doi:10.1186/1745-6215-10-27.

31. Brown A et al. The development and trial of a new approach to pharmaceutical competency development for primary healthcare personnel in Pacific Island countries. Pharm Educ. 2015;15(1):69-75.

32. Obiols LA. Higher level practice in clinical pharmacy specialties: application of the advanced level competency framework and implications for consultant pharmacists. PhD Thesis. School of Pharmacy, University of London. 2008.

33. Meštrović A et al. Evaluation of Croatian community pharmacists' patient care competencies using the General Level Framework. Am J Pharm Educ. 2011;75(2).

34. Carrington $\mathrm{C}$ et al. The development of a competency framework for pharmacists providing cancer services. J Oncol Pharm Pract. 2011;17(3):168-178. doi:10.1177/1078155210365582.

35. Brown AN et al. Validated competency framework for delivery of pharmacy services in the Pacific Island countries. J Pharm Pract Res. 2012;42(4):268-272. doi:10.1002/j.2055-2335.2012.tb00186.x.

36. Olsen R. Self-selection bias. In: Lavrakas PJ, ed. Encyclopedia of Survey Research Methods. Thousand Oaks, CA: SAGE Publications, Inc.; 2008:809-811. 
Figure 1: Flow chart showing participant recruitment

463

464

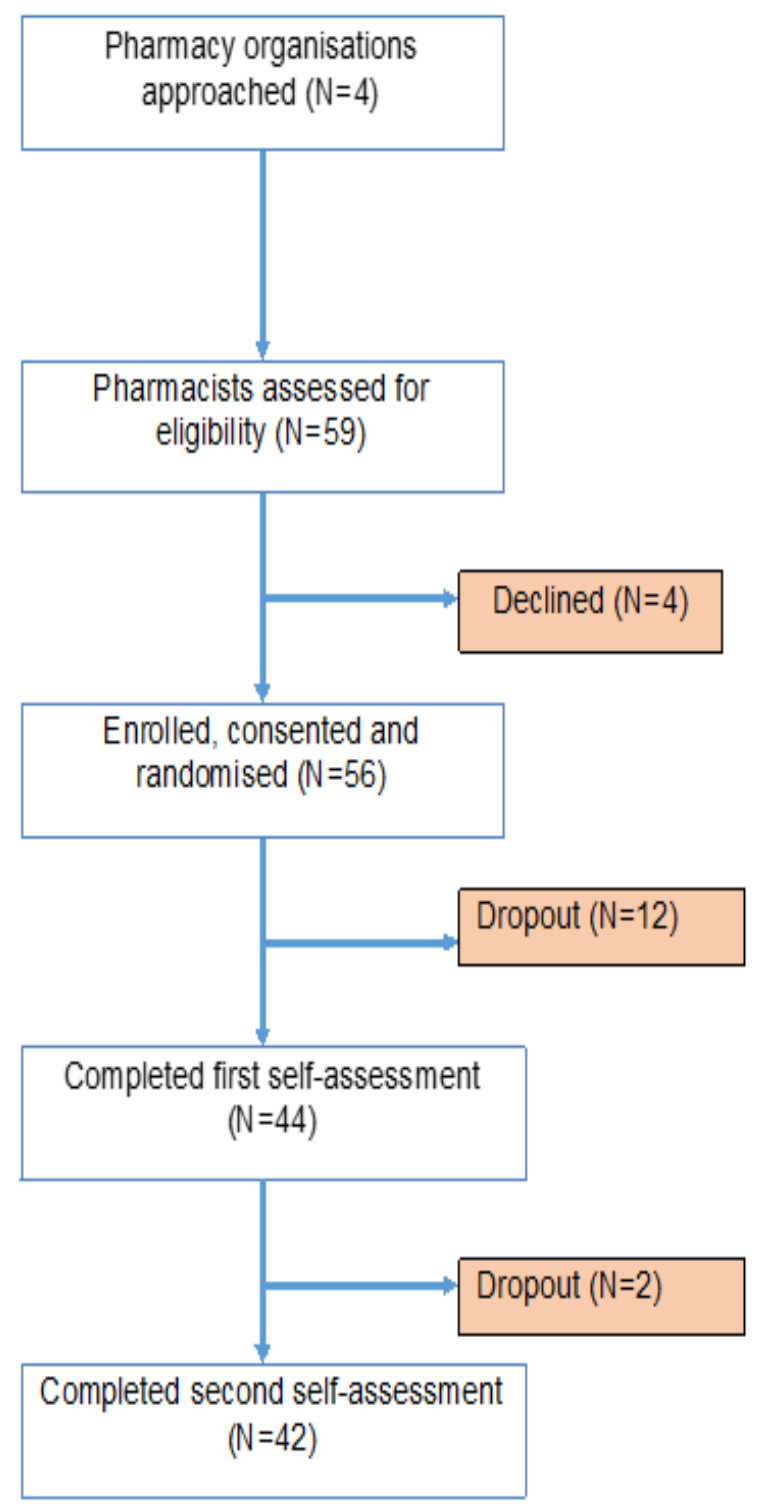

467 Programme: (Word/Mac) 
Figure 2: Evidence used to support self-assessment in the Expertise and Expert skills cluster

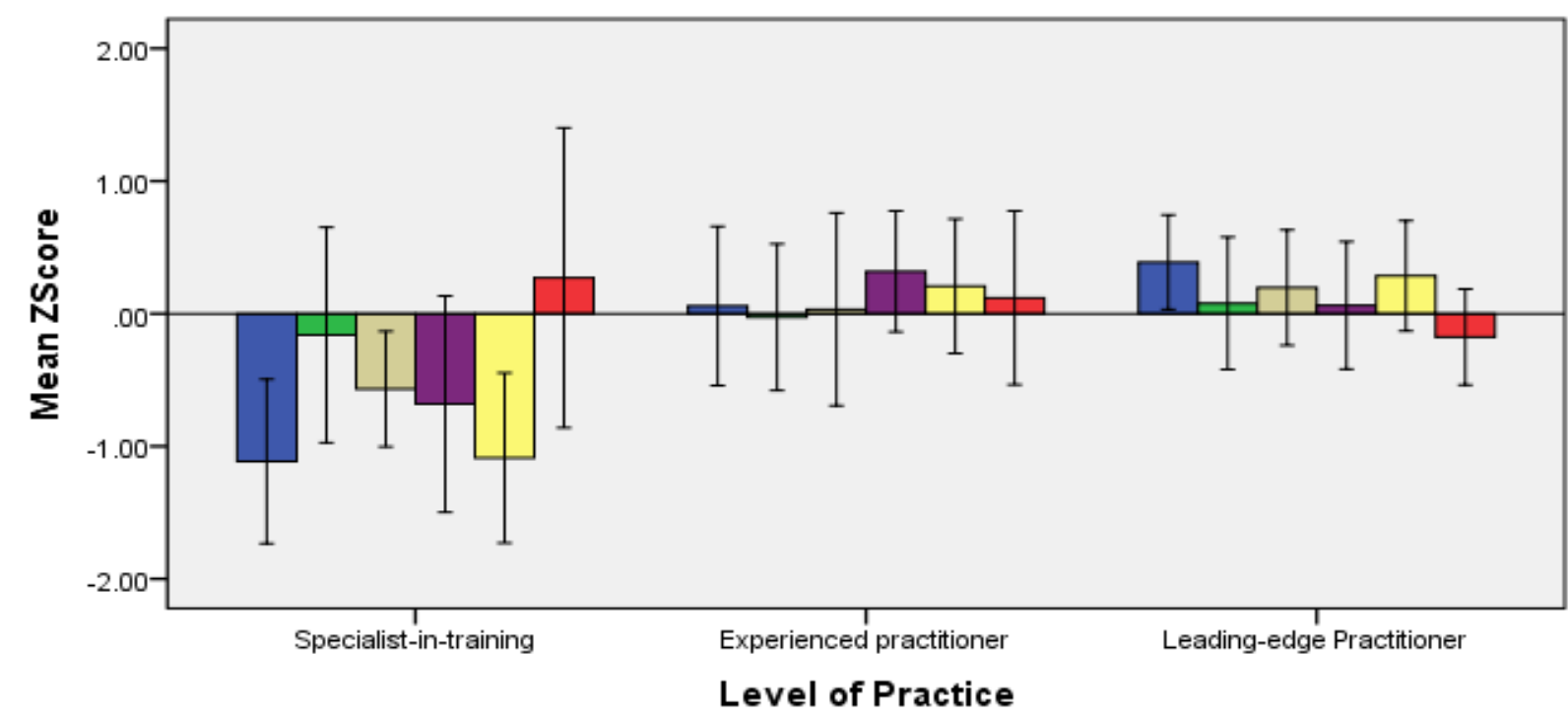

Error bars: $95 \% \mathrm{Cl}$

Committee member (local/ínternational)

Commee member (locan

Research role

Professional/expert recognition

$\square$ Managerial/eadership role

$\square$ other

Programme: (SPSS/Mac) 
Figure 3: Evidence used to support self-assessment in the Evaluation and Research cluster

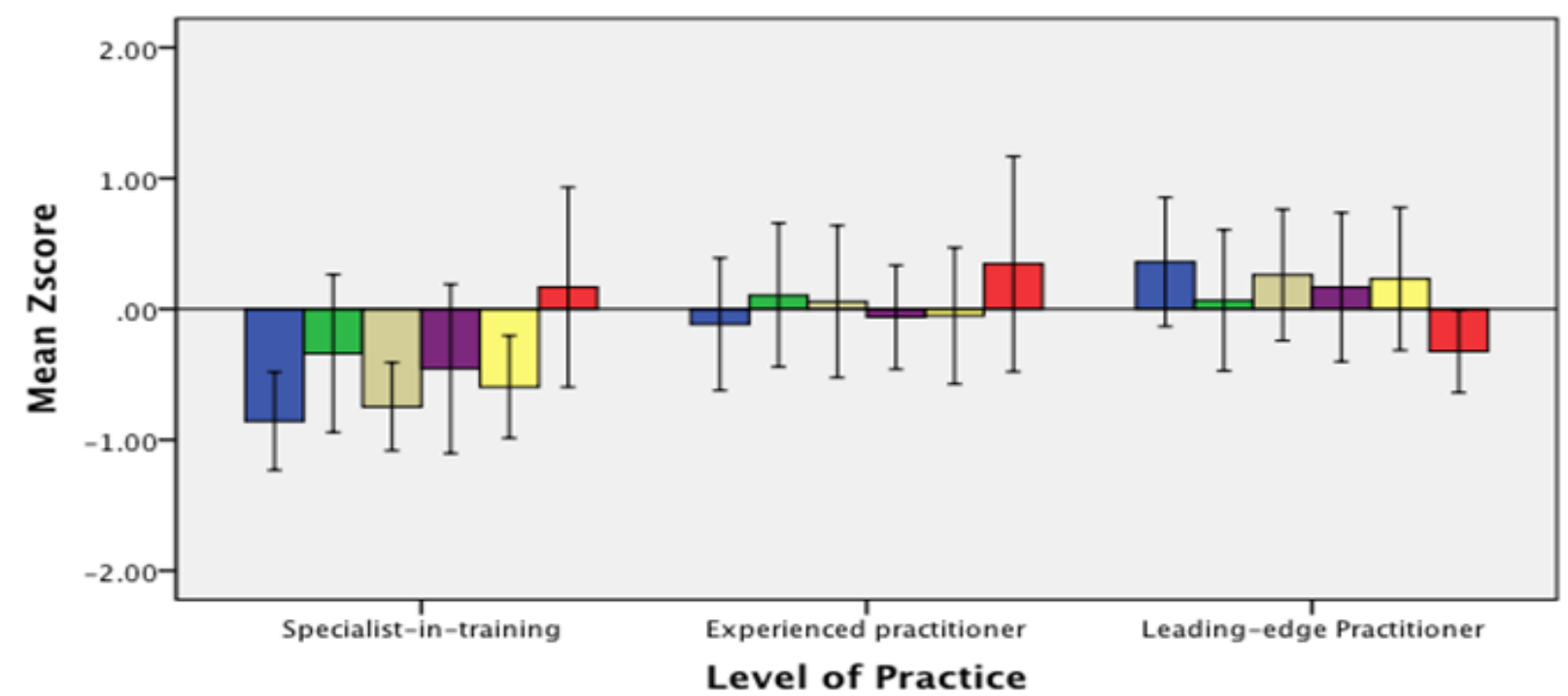

Error bars: $95 \% \mathrm{Cl}$

Committe member (local/international)

Education/teaching role

Research role

Profesional/expert recognition

Managerial/leadership role

Other

Programme: (SPSS/Mac) 
Table 1: Participants' self-assessed level of practice

\begin{tabular}{ll}
\hline Level of practice & N (\%) \\
\hline Specialist-in-training & $8(19)$ \\
Experienced practitioner & $10(24)$ \\
Leading-edge practitioner & $24(57)$ \\
\hline Total & $42(100)$ \\
\hline
\end{tabular}


Table 2: Within-subject Agreement per Competency

\begin{tabular}{|c|c|c|c|}
\hline Cluster & Competencies & N Agreement (\%) & $K$ statistic $(P)$ \\
\hline \multirow{4}{*}{ Expertise and Expert skills } & Expert skills & $28(67)$ & $0.424(<0.001)$ \\
\hline & Delivery of expertise & $23(55)$ & $0.253(0.024)$ \\
\hline & Professional autonomy & $32(76)$ & $0.516(<0.001)$ \\
\hline & Reasoning \& Judgement & $36(86)$ & $0.725(<0.001)$ \\
\hline \multirow{2}{*}{ Collaborative practice } & Communication & $27(64)$ & $0.376(0.002)$ \\
\hline & Team work & $27(64)$ & $0.352(0.004)$ \\
\hline \multirow{5}{*}{ Leadership } & Strategic context \& planning & $28(67)$ & $0.426(<0.001)$ \\
\hline & Governance & $18(43)$ & $0.130(0.214)$ \\
\hline & Vision & $29(69)$ & $0.558(<0.001)$ \\
\hline & Innovation \& service development & $27(64)$ & $0.455(0.001)$ \\
\hline & Motivation & $23(55)$ & $0.227(0.044)$ \\
\hline \multirow{8}{*}{ Management } & National priorities & $19(45)$ & $0.161(0.098)$ \\
\hline & Resource utilisation & $28(67)$ & $0.479(<0.001)$ \\
\hline & Standards of practice & $24(57)$ & $0.34(<0.001)$ \\
\hline & Managing risk & $23(55)$ & $0.328(0.001)$ \\
\hline & Managing performance & $20(48)$ & $0.215(0.016)$ \\
\hline & Project management & $24(57)$ & $0.357(<0.001)$ \\
\hline & Managing change & $28(67)$ & $0.474(<0.001)$ \\
\hline & Working across boundaries & $17(41)$ & $0.170(0.049)$ \\
\hline \multirow{5}{*}{$\begin{array}{l}\text { Education, Training } \quad \& \\
\text { Professional Development }\end{array}$} & Role model \& mentorship & $26(62)$ & $0.394(0.001)$ \\
\hline & Education \& training & $25(60)$ & $0.285(0.007)$ \\
\hline & Professional development & $24(57)$ & $0.299(0.006)$ \\
\hline & Link practice to education & $26(62)$ & $0.420(0.001)$ \\
\hline & Educational policy & $30(71)$ & $0.600(<0.001)$ \\
\hline \multirow{6}{*}{ Evaluation \& research } & Critical evaluation & $22(52)$ & $0.289(0.005)$ \\
\hline & Identifies gaps in evidence base & $24(57)$ & $0.382(<0.001)$ \\
\hline & Develops \& evaluates research protocols & $25(60)$ & $0.466(<0.001)$ \\
\hline & Apply research evidence & $21(50)$ & $0.351(<0.001)$ \\
\hline & Supervises others undertaking research & $25(60)$ & $0.551(<0.001)$ \\
\hline & Establishes research partnerships & $24(57)$ & $0.539(<0.001)$ \\
\hline
\end{tabular}


Table 3: Median Rank per Competency Cluster

\begin{tabular}{|c|c|c|c|}
\hline \multirow[b]{2}{*}{ Cluster } & \multicolumn{2}{|l|}{ Median rank } & \multirow[t]{2}{*}{ Wilcoxon sum $\operatorname{rank} Z(p)$} \\
\hline & $1^{\text {st }}$ Assessment & $2^{\text {nd }}$ Assessment & \\
\hline Expertise and Expert Skills & 10 & 10 & $-0.838(0.402)$ \\
\hline Collaborative Practice & 5 & 5 & $-2.027(0.043)$ \\
\hline Leadership & 13 & 14 & $-0.897(0.37)$ \\
\hline Management & 18.5 & 19.5 & $-1.197(0.231)$ \\
\hline $\begin{array}{l}\text { Education, Training \& Professional } \\
\text { Development }\end{array}$ & 12 & 12 & $-0.543(0.587)$ \\
\hline Evaluation \& Research & 13 & 13.5 & $-1.465(0.143)$ \\
\hline
\end{tabular}


